\title{
IMMANUEL WALLERSTEIN, 1930-2019
}

I

mmanuel Wallerstein nació el 18 de septiembre de 1930 y murió el pasado 31 de agosto de 2019. Inicialmente especialista en África, tema sobre el cual desarrolló su tesis doctoral, Wallerstein llegó a ser ampliamente conocido por el análisis de sistema-mundo (world-systems approach). En este enfoque, Wallerstein trasciende, por primera vez en términos de teoría social sistemática, el nacionalismo metodológico en que buena parte del pensamiento del siglo XX había estudiado el mundo moderno. El enfoque de Wallerstein arranca de una insatisfacción epistemológica. Para él es evidente que la realidad es construida, aunque ello supone a la vez asumir que la construcción es realmente social, y que por tanto hay que realizar una constante reflexión sobre los lentes con que se mira esa realidad. Esto lo conduce a la necesidad de observar la formación de procesos sociales con mirada multidisciplinar (Wallerstein 2019a).

En base a una aproximación de este tipo — que combina conocimientos históricos, sociológicos, económicos politológicos y antropológicos-, Wallerstein delinea el proceso que conduce fundamentalmente a la formación de una economía-mundo, de una política-mundo y de una geocultura, esto es, de estructuras de conocimiento global que acompañan a los mecanismos de construcción del sistema-mundo. La tesis central de Wallerstein es que la expansión del capitalismo, desde el siglo XIX, "ha generado una necesidad de constante cambio tecnológico, una constante expansión de fronteras - en sentido geográfico, psicológico, intelectual y científico" (Wallerstein 2004, 2).

Estas tendencias se consolidaron hacia 1945 con la posición hegemónica de Estados Unidos, las turbulencias políticas del denominado Tercer Mundo, su búsqueda de autoafirmación, y una expansión de la economía mundial y de tendencias democratizadoras que condujeron 
al despliegue de un sistema universitario mundial. Sin embargo, para Wallerstein, el largo período de hegemonía liberal comenzó a desestabilizarse con la revolución de 1968, provocando una fuerte contradicción entre el cambio de la geocultura y las instituciones políticas que permanecieron intactas. Esto conduce a ingentes shocks culturales que, unidos a tendencias estructurales de acumulación capitalista que se suman a una creciente desilusión por movimientos populares en el poder incapaces de transformar las condiciones de desigualdad global, constituyen la crisis del sistema-mundo contemporáneo. En una formulación que muestra su capacidad de integrar teoría y conocimiento histórico, dice Wallerstein que 1968 "desestructuró la dominancia automática del centro liberal que había prevalecido en el sistema mundial desde antes de la revolución de 1848. La derecha y la izquierda se liberaron de su rol de íconos del liberalismo centrista y fueron capaces de afirmar, o más bien reafirmar, sus valores más radicales" (Wallerstein 2004, 85).

¿Qué podemos esperar de esta situación que solo se inicia culturalmente en 1968 ? - se pregunta Wallerstein a inicios del siglo XXI. Su respuesta es dramáticamente actual: salvajes fluctuaciones en todos los campos institucionales del sistema-mundo. Esto se traduce en presiones especulativas en la economía-mundo que se salen del control de las instituciones financieras, en altos niveles de violencia en la política-mundo sin que nadie tenga la capacidad de control, y en una fuerte disminución de formas morales integrativas previamente impulsadas por el Estado e instituciones religiosas. Se trata de una crisis sistémica, ante la cual los ajustes de mediano plazo tienen poco efecto; una crisis en sentido fuerte, una que no puede ser resuelta dentro de los marcos del mismo sistema y que, por tanto, abre un período de radical transición, en el que la lucha, la incertidumbre y un cuestionamiento de las estructuras de conocimiento están a la orden del día. En tal transición, las alternativas de futuro se bifurcan entre un sistema jerárquico que permite privilegios de acuerdo a rangos y un sistema relativamente democrático e igualitario. Si bien el moderno sistema-mundo nos ha llevado a esta crisis, al menos ha permitido aclarar las condiciones de esta pregunta, enfrentarla en toda su radicalidad y actuar en la dirección que prefiramos; nos pone ante la posibilidad de creación, "o al menos de contribuir a la creación de algo que pueda llenar de mejor modo nuestras posibilidades colectivas" (Wallerstein 2004, 90). 
Un intelectual tan completo como Wallerstein (con influencias clásicas tales como Adam Smith, Joseph Schumpeter, Karl Marx, y contemporáneas como Frantz Fanon, Karl Polanyi e Ilya Prigogine) no puede ser cubierto realmente en sus múltiples intereses y particularidades. Los autores de este simposio, en homenaje a su memoria y a lo que nos enseña del mundo actual, tocan sus aspectos centrales. El texto de Hugo Cadenas entrega una prolija visión del core de la argumentación de Wallerstein a lo largo de su carrera intelectual, así como de las consecuencias políticas que este pensamiento deriva en términos de libertad e igualdad. El análisis de Nathaly Mancilla, por su parte, tiene el valor intelectual de posicionar a Wallerstein en la discusión actual sobre sociedad mundial y de reencontrar ahí su aporte al pensamiento contemporáneo con un especial énfasis en el rol del derecho. Finalmente, la contribución de Julio Labraña, José Joaquín Brunner y Javier Álvarez se interna con precisión en un aspecto fundamental del pensamiento de Wallerstein, el concepto de geocultura y su traducción en el sistema universitario moderno.

En un último comentario en su página electrónica, fechado el 1 julio de 2019, Wallerstein (2019b) sentenció: "pienso que hay 50 y 50 de posibilidades de cambio transformacional, pero solo 50 y 50 ". Dos meses después dejó de existir, pero su pensamiento permanecerá actual, especialmente en tiempos de crisis.

Aldo Mascareño

\section{BIBLIOGRAFÍA}

Wallerstein, I. 2004. World-Systems Analysis. An Introduction. Duke: Duke University Press.

Wallerstein, I. 2019a [2000]. The Development of an Intellectual Position. Disponible en: https://iwallerstein.com/intellectual-itinerary/ [26 de noviembre 2019].

Wallerstein, I. 2019b. This Is the End; this Is the Beginning. Disponible en: https:// iwallerstein.com/category/commentaries/ [26 de noviembre 2019]. 